Article

\title{
Investigation on the Effects of MXene and $\beta$-Nucleating Agent on the Crystallization Behavior of Isotactic Polypropylene
}

\author{
Wanxin Peng ${ }^{1}$, Jian Kang ${ }^{1, * \mathbb{C}}$, Xiuduo Song ${ }^{2, *}$, Yue Zhang ${ }^{3}$, Bo $\mathrm{Hu}^{3}$, Ya Cao ${ }^{1}$ and Ming Xiang ${ }^{1}$ \\ 1 State Key Laboratory of Polymer Materials Engineering, Polymer Research Institute of Sichuan University, \\ Chengdu 610065, China; kelly_520_peng@163.com (W.P.); caoya@scu.edu.cn (Y.C.); \\ xiangming@scu.edu.cn (M.X.) \\ 2 Key Laboratory of Combustion and Explosion Technology, Xi'an Modern Chemistry Research Institute, \\ Xi'an 710065, China \\ 3 Dongfang Electric Machinery Co., Ltd., Deyang 618000, China; metaspark@163.com (Y.Z.); \\ nsno1@163.com (B.H.) \\ * Correspondence: jiankang@scu.edu.cn (J.K.); song_xd@126.com (X.S.)
}

check for updates

Citation: Peng, W.; Kang, J.; Song, X.; Zhang, Y.; Hu, B.; Cao, Y.; Xiang, M. Investigation on the Effects of MXene and $\beta$-Nucleating Agent on the Crystallization Behavior of Isotactic Polypropylene. Polymers 2021, 13, 2931. https://doi.org/10.3390/ polym13172931

Academic Editor:

Mohammad Arjmand

Received: 5 August 2021

Accepted: 27 August 2021

Published: 31 August 2021

Publisher's Note: MDPI stays neutral with regard to jurisdictional claims in published maps and institutional affiliations.

Copyright: (c) 2021 by the authors. Licensee MDPI, Basel, Switzerland. This article is an open access article distributed under the terms and conditions of the Creative Commons Attribution (CC BY) license (https:// creativecommons.org/licenses/by/ $4.0 /)$

\begin{abstract}
The effects of MXene on the crystallization behavior of $\beta$-nucleated isotactic polypropylene (iPP) were comparatively studied. The commonly used MXene $\mathrm{Ti}_{3} \mathrm{C}_{2} \mathrm{~T}_{\mathrm{x}}$ was prepared by selective etching and its structure and morphology were studied in detail. Then MXene and a rare earth $\beta$-nucleating agent (NA) WBG-II were nucleated with iPP to prepare samples with different polymorphic compositions. The crystallization, melting behavior, and morphologies of neat iPP, iPP/MXene, iPP/WBG-II, and iPP/MXene/WBG-II were comparatively studied. The crystallization behavior analysis reveals that a competitive relationship exists between MXene and WBG-II when they were compounded as $\alpha$ and $\beta$ nucleating agents. In the system, the $\beta$-nucleation efficiency (NE) of WBG-II is higher than $\alpha$-NE of MXene. The $\beta$-phase has relatively low thermal stability and would transform to $\alpha$-phase when cooled below a critical temperature.
\end{abstract}

Keywords: isotactic polypropylene; MXene; $\beta$-nucleating agent; polymorphic crystallization behavior

\section{Introduction}

Isotactic polypropylene (iPP) is one of the most widely applied thermoplastic polymers due to its desirable properties, including good mechanical properties, excellent chemical and moisture resistance, versatile processability, and low manufacturing cost [1,2]. It is widely used in pipes, packing materials, and separators materials [3,4]. iPP is a semicrystalline polymer and exhibits polymorphic behavior [5], with a monoclinic $\alpha$-form, hexagonal $\beta$-form, triclinic $\gamma$-form [6] and a mesomorphic smectic form [7]. Among the crystallization forms, the monoclinic $\alpha$-form is the most common and stable one. The $\beta$-form is metastable and can only be obtained via special processing conditions such as directional crystallization in a temperature gradient [8], shear-induced crystallization $[9,10]$, and the introduction of a selective $\beta$ nucleating agent $[2,11]$. Among these methods, introducing a $\beta$-nucleating agent is the most effective way to access high $\beta$-phase content.

It is known that crystalline morphology and polymorphic behavior significantly affect the structure and properties of polymers. When adding a small amount of $\beta$-NA into iPP, the impact strength and toughness exceed that of $\alpha$-iPP [12]. This enhanced toughness and ductility can be attributed to energy dissipation during the yield process accompanied by $\beta$ to $\alpha$ transformation [13]. While $\beta$-iPP improves the toughness, the stiffness decreases compared with $\alpha$-iPP. Thereby, compounding iPP with both $\alpha$ - and $\beta$ - NA has become a potential way of balancing stiffness and toughness and has been widely studied. Wang et al. [14] compounded $\beta$-NA calcium pimelate with multi-walled carbon nanotubes (CNTs) and found the composites exhibited superior impact strength without a significant decrease in stiffness and strength. They attributed this improvement 
to the enhanced nucleating ability. Kang et al. [15] studied the crystallization behavior of CNTs compounded with $\beta$-NA WBG-II and proposed a new pathway to control the final polymorphic composition. Moreover, they found that CNTs play a leading role in the system of iPP/CNTs/WBG-II due to the higher nucleation efficiency of CNTs. The findings were also supported by the principle of determining the crystallization form of iPP nucleated with both $\alpha$ - and $\beta$ - NA proposed by Zhong et al. [16].

MXenes are a group of 2D materials that are synthesized from ternary transition metal carbides/nitrides (MAX phase). The general formula of MXenes and MAX is $M_{n+1} X_{n} T_{X}$ and $M_{n+1} A X_{n}$, where $n$ varies from 1 to $3, M$ is an early transitional metal element, $X$ is carbon or nitrogen, $T_{X}$ is a surface termination species such as $\mathrm{F}$ or/and $\mathrm{Cl}$ [17]. The MAX phase possesses a layered hexagonal structure in which the A-layers atoms are relatively weakly bound and act as reactive sites for removal. In 2011, the Gogotsi team firstly successively synthesized $2 \mathrm{D} \mathrm{Ti}{ }_{3} \mathrm{C}_{2} \mathrm{~T}_{\mathrm{x}}$ nanosheets by selectively etching $\mathrm{Al}$ atoms from a layered $\mathrm{Ti}_{3} \mathrm{AlC}_{2}$ ternary carbide in hydrochloric acid [18]. They called the resulting 2D materials "MXene" due to their graphene-like morphology. Since then, this discovery has led to numerous studies on the synthesis of MXenes because of the large number of MAX phase precursors available. Nowadays, over $60 \mathrm{MAX}$ phases are known and about 30 different MXenes have been synthesized, and among them, $\mathrm{Ti}_{3} \mathrm{C}_{2} \mathrm{~T}_{\mathrm{X}}$ is the most promising material and has been studied most widely $[18,19]$.

Like other 2D materials, the unique structure, outstanding chemical and physical properties, and wide range of stoichiometric compositions [20] of MXenes have great potential applications in many fields such as energy storage [21] and MXene-polymer composites [22]. Currently, there are a few studies on MXene-polymer composites. Ling et al. [23] firstly introduced $\mathrm{Ti}_{3} \mathrm{C}_{2} \mathrm{~T}_{\mathrm{x}}$ into poly(vinyl alcohol) (PVA) and poly(diallyl dimethylammonium chloride) (PDDA). They found that the composite films exhibit improved conductivities and mechanical strength and suggested that MXenes are promising fillers for multifunctional polymer composites. Zhang et al. [24] prepared $\mathrm{Ti}_{3} \mathrm{C}_{2} \mathrm{~T}_{\mathrm{x}} /$ ultrahigh molecular weight polyethylene (UHMWPE) composites by melt mixing and found that both the thermal and mechanical properties of the composites were improved with very low $\mathrm{Ti}_{3} \mathrm{C}_{2} \mathrm{~T}_{\mathrm{x}}$ loading levels. The tensile and breaking strengths of the composites were enhanced and reached maximum values at $0.75 \mathrm{wt} \% \mathrm{Ti}_{3} \mathrm{C}_{2} \mathrm{~T}_{\mathrm{x}}$. Shi et al. [25] fabricated $\mathrm{Ti}_{3} \mathrm{C}_{2} \mathrm{~T}_{\mathrm{x}} / \mathrm{PP}$ composites to improve the mechanical properties via nanoconfinement structure and physical barrier of $\mathrm{Ti}_{3} \mathrm{C}_{2} \mathrm{~T}_{\mathrm{x}}$ nanosheets. In their work, the results revealed that the tensile strength and ductility were improved simultaneously by $35.3 \%$ and $674.6 \%$.

While these works focus on the effects on the physical properties of MXene/polymer composites, studies on their crystallization processes have been less reported. Cao et al. [26] prepared 2D MXene nanosheets/linear low-density polyethylene (LLDPE) by melt mixing to investigate the crystallization process. They found that $2 \mathrm{wt} \%$ MXene can enhance the crystallization rate of LLDPE while excessive amounts of MXene such as $4 \mathrm{wt} \%$ would retard the rate. Shi et al. [25] found that at low content $(<1 \mathrm{wt} \%)$ of MXene, the crystallization temperature moved towards lower values. However, when the concentration of MXene exceeded $1 \mathrm{wt} \%$ the crystallization temperature started to rise. In our previous work, we studied the effects of MXene on the non-isothermal crystallization behavior of iPP [27]. When from $0 \mathrm{wt} \%$ to $0.5 \mathrm{wt} \%$ MXene was added, the crystallization peak temperature and crystallization rate both increased, indicating the crystallization process was promoted. Once the concentration of MXene reached $1 \mathrm{wt} \%$, the crystallization process showed a reverse trend. Since crystallization plays a key role in the physical and mechanical properties, understanding the effects of MXene on the crystallization behaviors of polymers is of great importance. Therefore, this work chose the most common MXene, $\mathrm{Ti}_{3} \mathrm{C}_{2} \mathrm{~T}_{\mathrm{x}}$, and comparatively studied its effects on the crystallization and polymorphic behavior of $\beta$-iPP by differential scanning calorimetry (DSC), wide-angle X-ray diffraction (WAXD), and polarized light optical microscopy (PLOM), so as to provide new understanding of the preparation of $\beta$-iPP/MXene composites with tunable polymorphic behavior and morphologies. 


\section{Experimental Section}

\subsection{Materials}

Isotactic polypropylene (iPP, trade name $\mathrm{T} 38 \mathrm{~F}$ ) with average isotacticity around $97.6 \%$ and molecular weight $347,000 \mathrm{gmol}^{-1}$ was provided by Lanzhou PetroChemical Corp. (Lanzhou, China). To prevent iPP from degrading, a small amount of antioxidant (Irganox 1010, BASF Corp., Ludwig, Germany) was added during the mixing process.

The $\beta$-nucleating agent ( $\beta$-NA, trade name WBG-II) was supplied by Guangdong Winner Functional Materials Corp. (Foshan, China). WBG-II, a rare earth complex nucleating agent, is a commonly used commercial nucleating agent. It has a general formula $\mathrm{Ca}_{\mathrm{x}} \mathrm{La}_{1-x}(\mathrm{LIG} 1)_{\mathrm{m}}(\mathrm{LIG} 2)_{\mathrm{n}}$, where $x$ and $1-x$ are the proportion of $\mathrm{Ca}^{2+}$ and $\mathrm{La}^{3+}$ ions, respectively, and LIG1 and LIG2 are dicarboxylic acid and amide-type ligands [13,28].

The MAX phase, $\mathrm{Ti}_{3} \mathrm{AlC}_{2}$ powder (99\% purity, 400 mesh), was purchased from 11 Technology Co. Ltd. (Beijing, China). Concentrated hydrochloric acid $(\mathrm{HCl}, 37 \mathrm{wt} \%)$ was purchased from Chengdu Kelong Chemical Reagent Factory (city, China). Lithium fluoride (LiF) with $99 \%$ purity was purchased from Aladdin Bio-Chem Technology Co. Ltd. (Shanghai, China).

\subsection{Sample Preparation}

\subsubsection{Synthesis of $\mathrm{Ti}_{3} \mathrm{C}_{2} \mathrm{~T}_{\mathrm{x}}$}

This work used hydrochloric acid $(\mathrm{HCl})$ and $\mathrm{LiF}$ to form $\mathrm{HF}$ in situ and selectively etch $\mathrm{Ti}_{3} \mathrm{AlC}_{2}$. In the first step, $\mathrm{LiF}$ was dissolved in dilute $\mathrm{HCl}(6 \mathrm{M})$ for 5 min under magnetic stirring. Then $\mathrm{Ti}_{3} \mathrm{AlC}_{2}$ powder was slowly added over $10 \mathrm{~min}$ to avoid any overheating caused by the exothermic nature of the reaction. Then the solution was continuously heated for $24 \mathrm{~h}$ at $40{ }^{\circ} \mathrm{C}$ under magnetic stirring. When the etching was completed, the solution was centrifuged at $8000 \mathrm{rpm}$ for $10 \mathrm{~min}$ and then washed with distilled water. This washing process was repeated to remove the residual reaction products until the $\mathrm{pH}$ of the supernatant was around 7 . Then the sediment was then added with distilled water and placed in an ice-water bath followed by $2 \mathrm{~h}$ of ultrasonication and then centrifugation. The resulting suspension was dried under vacuum.

\subsubsection{Synthesis of $\beta$-iPP $/ \mathrm{Ti}_{3} \mathrm{C}_{2} \mathrm{~T}_{x}$ Composites}

The samples were prepared in two steps. Firstly, the $\mathrm{Ti}_{3} \mathrm{C}_{2} \mathrm{~T}_{\mathrm{x}}$ and WBG-II were respectively mixed with iPP granules in a Mini-Lab Extruder (HAAKE MiniLab II, Haake Thermo Scientific, Waltham, MA, USA) at a melting temperature of $200{ }^{\circ} \mathrm{C}$ and a screw speed $60 \mathrm{rpm}$ to obtain two types of master batch. Then the master batches were mixed with iPP again in a certain ratio to prepare four samples with different compositions. After that, the mixture was compressed by a pressure molding machine at $7 \mathrm{MPa}$ and $190{ }^{\circ} \mathrm{C}$ for further characterization. To benefit our discussion, the samples were named as iPP, $\mathrm{iPP} / \mathrm{WBG}-\mathrm{II}, \mathrm{iPP} / \mathrm{MXene}$, and iPP/MXene/WBG-II, where the concentrations of $\mathrm{Ti}_{3} \mathrm{C}_{2} \mathrm{~T}_{\mathrm{x}}$ and WBG-II were fixed at $0.5 \mathrm{wt} \%$ and $0.3 \mathrm{wt} \%$, respectively. The concentrations were chosen based on some previous studies in $\beta$-NA [29-32].

\subsection{Characterization}

\subsubsection{Differential Scanning Calorimetry}

All the calorimetric experiments were conducted using a Mettler Toldeo DSC1 instrument (Mettler Corp., Zurich, Switzerland) under a nitrogen flow of $50 \mathrm{~mL} \mathrm{~min}{ }^{-1}$. For each measurement, 2-5 mg samples were weighed and then subjected to the following standard thermal treatment: the sample was firstly heated to $200{ }^{\circ} \mathrm{C}$ and held for $5 \mathrm{~min}$ to erase thermal history, then cooled to end temperature of $50^{\circ} \mathrm{C}$ at $10^{\circ} \mathrm{C} / \mathrm{min}$ to crystallize. Finally, it was heated back to $200{ }^{\circ} \mathrm{C}$ at $10^{\circ} \mathrm{C} / \mathrm{min}$. The cooling and heating curves were recorded to analyze the crystallization and melting behavior of the samples. It is worth noting that to ensure the accuracy of the data, each sample was repeatedly tested five to eight times to obtain the average values. 
The relative content of $\beta$-crystal $\left(\beta_{c}\right)$ can be calculated by the following equation [33-35]:

$$
\beta_{c}=\frac{(1-\lambda)_{\beta}}{(1-\lambda)_{\alpha}+(1-\lambda)_{\beta}}
$$

where the crystallinity of each phase $(1-\lambda)$ is calculated by $\Delta H / \Delta H_{u} . \Delta H$ and $\Delta H_{u}$ are the melting enthalpy and the complete melting enthalpy of crystals, where the $\Delta H_{u}$ for $100 \%$ crystalline iPP is $209 \mathrm{~J} / \mathrm{g}$ [36]. Then the crystallinity of $\beta$-crystals $X_{\beta}$ is derived by multiplying the crystallinity $X_{c}$ and relative content of $\beta$-crystals $\beta_{c}$ [37].

\subsubsection{Wide-Angle X-ray Diffraction}

The WAXD patterns were recorded by an Ultima IV diffractometer (Rigaku, Tokyo, Japan). A conventional $\mathrm{Cu} K_{\alpha}$ (wavelength $\lambda=0.154 \mathrm{~nm}$ ) X-ray tube at a voltage of $40 \mathrm{kV}$ and filament current of $40 \mathrm{~mA}$ was used to obtain the spectra in the $2 \theta$ range of 5-30 ${ }^{\circ}$. The scanning rate was $10^{\circ} / \mathrm{min}$ and the scanning step is $0.04^{\circ}[38,39]$. The relative content of the $\beta$-crystal phase can be determined by the following equation $[40,41]$ :

$$
k_{\beta}=\frac{H_{\beta}(300)}{H_{\beta}(300)+H_{\alpha}(110)+H_{\alpha}(040)+H_{\alpha}(130)}
$$

where $k_{\beta}$ denotes the relative content of $\beta$-crystal; $H_{\alpha}(110), H_{\alpha}(040)$, and $H_{\alpha}(130)$ are the intensities of three strongest diffraction peaks of monoclinic $\alpha$-form; $H_{\beta}(300)$ is the intensity of the strongest diffraction peak of hexagonal $\beta$-form.

The crystal size $L$ was calculated from the WAXD data by Scherrer's equation:

$$
L=\frac{k \lambda}{\beta \cos \theta}
$$

where $\beta$ is the diffraction line width at half maximum (FWHM) intensity in radians, $\theta$ is the diffraction angle at the maximum peak, and $\mathrm{k}$ is the shape factor and the value is taken as 0.9 .

\subsubsection{Polarized Light Optical Microscopy}

The hierarchical crystalline morphologies during crystallization were studied by polarized light optical microscopy (Eclipse LV100 POL, Nikon, Tokyo, Japan) equipped with a hot-stage (Linkam Scientific Instruments Ltd., Tadworth, UK). The sample was cut into small pieces, placed between two glass covers, and melted at $200{ }^{\circ} \mathrm{C}$ [42-44]. Then the sample was pressed into a thin film and slowly cooled to room temperature to allow full crystallization. The online PLOM tests were performed to observe the evolution of hierarchical crystalline morphologies. During the process, the samples were firstly heated to $200{ }^{\circ} \mathrm{C}$ at $20^{\circ} \mathrm{C} / \mathrm{min}$ for $5 \mathrm{~min}$ to erase thermal history, then fast cooled to $140{ }^{\circ} \mathrm{C}$ at $50{ }^{\circ} \mathrm{C} / \mathrm{min}$. After that, the sample was held at the temperature, and PLOM images were recorded at different times.

\subsubsection{Scanning Electron Microscopy}

The morphology of precursor $\mathrm{Ti}_{3} \mathrm{AlC}_{2}$ and $\mathrm{Ti}_{3} \mathrm{C}_{2} \mathrm{~T}_{\mathrm{x}}$ was observed by SEM (Apreo $\mathrm{S}$ HiVoc, Thermo Fisher Scientific Corp., Waltham, MA, USA).

\subsubsection{Transmission Electron Microscope}

To further investigate the structure of $\mathrm{Ti}_{3} \mathrm{C}_{2} \mathrm{~T}_{\mathrm{x}}$, TEM (Tecnai G2 F20 S-TWIN, FEI Corp., Hillsboro, OR, USA) was performed under an accelerating voltage of $200 \mathrm{kV}$. To prepare the TEM sample, the $\mathrm{Ti}_{3} \mathrm{C}_{2} \mathrm{~T}_{\mathrm{x}}$ was dispersed in distilled water under ultrasonication for $10 \mathrm{~min}$, then the dispersion was dropped on the copper grid for observation. 


\section{Results and Discussions \\ 3.1. Structure and Morphology of MXene}

The morphologies of bulk $\mathrm{Ti}_{3} \mathrm{AlC}_{2}$ and $\mathrm{Ti}_{3} \mathrm{C}_{2} \mathrm{~T}_{\mathrm{x}}$ were observed by scanning electron microscopy (SEM) as shown in Figure 1. From Figure 1a, it can be observed that the bulk $\mathrm{Ti}_{3} \mathrm{AlC}_{2}$ has a stacked layered structure. After the process is completed, the structure shows a relatively weak stacked structure, which can also be called an accordion-like structure. This expanded interlayer structure suggests the successive removal of Al layer and exfoliation of MXene flakes and might be caused by the escape of $\mathrm{H}_{2}$ gas during the exothermic reaction during the etching process $[45,46]$.
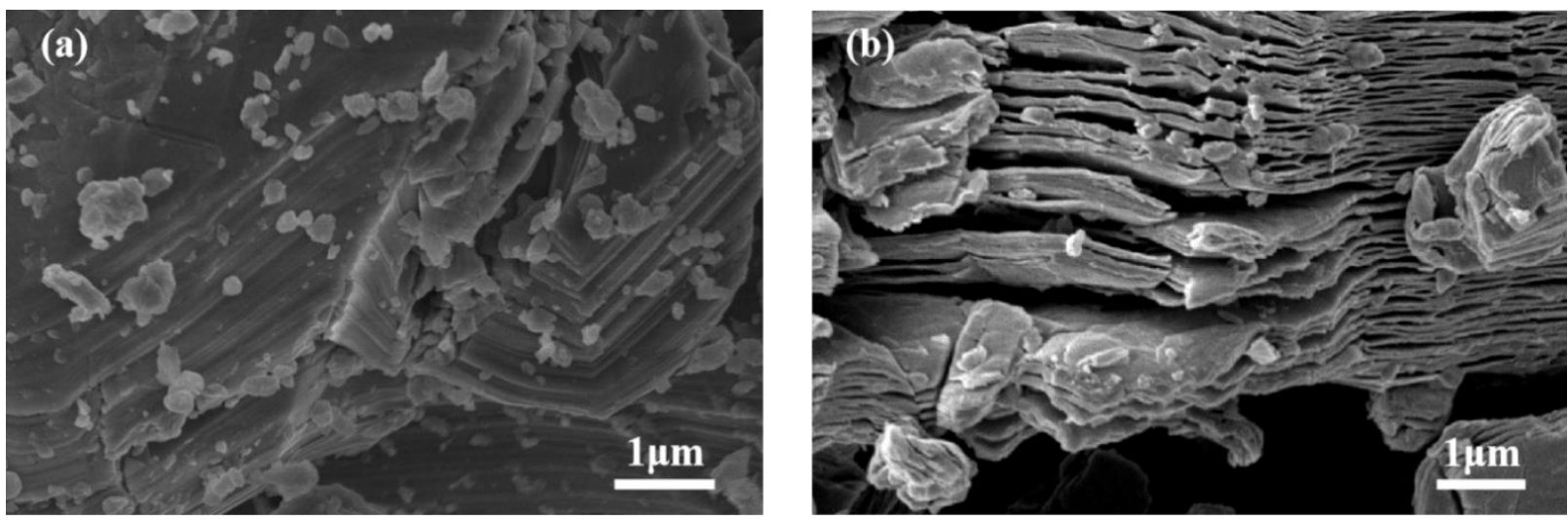

Figure 1. SEM images of $(\mathbf{a}) \mathrm{Ti}_{3} \mathrm{AlC}_{2}$ and $(\mathbf{b}) \mathrm{Ti}_{3} \mathrm{C}_{2} \mathrm{~T}_{\mathrm{x}}$ before and after etching.

Figure 2 exhibits the dispersion of $\mathrm{Ti}_{3} \mathrm{AlC}_{2}$ and $\mathrm{Ti}_{3} \mathrm{C}_{2} \mathrm{~T}_{\mathrm{x}}$ in distilled water at different times. From Figure 2a1-a3, it can be observed that the $\mathrm{Ti}_{3} \mathrm{AlC}_{2}$ precursor could not maintain a stable distribution in distilled water. After etching, $\mathrm{Ti}_{3} \mathrm{C}_{2} \mathrm{~T}_{\mathrm{x}}$ can disperse homogeneously in distilled water even after a week (Figure $2 \mathrm{~b} 1-\mathrm{b} 3$ ). The digital photo in Figure $3 \mathrm{~b}$ shows that the diluted $\mathrm{Ti}_{3} \mathrm{C}_{2} \mathrm{~T}_{\mathrm{x}}$ dispersion in distilled water is stable, and the Tyndall effect can be observed under a red laser beam. TEM image in Figure $3 a$ indicates that the $\mathrm{Ti}_{3} \mathrm{C}_{2} \mathrm{~T}_{\mathrm{x}}$ dispersion contains single flakes with distinct edges and sizes of a few hundred nanometers. The $\mathrm{Ti}_{3} \mathrm{C}_{2} \mathrm{~T}_{\mathrm{x}}$ flake size can vary from a few hundred nanometers to a few microns by varying the synthesis route. There are also studies indicating that the electrical, chemical and electrochemical properties can be adjusted with respect to different lateral flake sizes, however precise control over the size still remains as a challenge [47].

The X-ray diffraction (XRD) plot in Figure $3 \mathrm{~b}$ showed that the most intense and representative peak of $\mathrm{Ti}_{3} \mathrm{AlC}_{2}$ at $2 \theta \approx 39^{\circ}$ that is assigned to (104) plane has disappeared after etching, indicating the successful removal of $\mathrm{Al}$ atom in the structure $[48,49]$. Moreover, the (002) peak has broadened and shifted from $9.5^{\circ}$ to $6.5^{\circ}$. This lower shift of (002) peak implies an increasing interlayer distance, which is consistent with the results from SEM images and is possibly caused by the removal of the Al layer in bulk structure and the introduction of surface terminations [45]. The results of SEM, TEM and XRD confirm the successful synthesis of $2 \mathrm{D} \mathrm{Ti}_{3} \mathrm{C}_{2} \mathrm{~T}_{\mathrm{x}}$ MXene.

\subsection{Crystallization Behavior of $\beta$-iPP/MXene Composites}

To comparatively study the crystallization behavior of neat iPP, iPP/WBG-II, iPP/MXene, and $\mathrm{iPP} / \mathrm{MXene} / \mathrm{WBG}-\mathrm{II}$, the DSC test procedure was applied as described in the experimental section. The obtained cooling curves are shown in Figure 4 . The variations in crystallization parameters including the onset, peak, end crystallization temperatures $\left(\mathrm{T}_{\text {conset, }}\right.$ $\mathrm{T}_{\mathrm{c}}$, and $\left.\mathrm{T}_{\mathrm{cend}}\right)$, and the crystallization peak width $\left(\mathrm{T}_{\text {conset }}-\mathrm{T}_{\text {cend }}\right)$ of different samples are plotted in Figure 5.

Figure 4 illustrates that when $\beta$-NA WBG-II is introduced into iPP, the crystallization peak temperature of iPP/WBG-II improves by $10.6^{\circ} \mathrm{C}$, and a strong $\beta$-form melting peak 
can be observed between the temperature range of $150-155{ }^{\circ} \mathrm{C}$ as revealed in the next section. Moreover, when MXene is introduced, the crystallization peak shifts towards higher temperature, $\mathrm{T}_{\mathrm{c}}$ of iPP/MXene increases by $3{ }^{\circ} \mathrm{C}$, and only the existence of $\alpha$-form melting peak is observed in the heating curve. In addition, Figure 5 shows that $T_{\text {conset }}$ and $\mathrm{T}_{\text {cend }}$ of iPP/WBG-II and iPP/MXene also increase. This shift of crystallization peak suggests that the crystallization could take place at a higher temperature, thereby the addition of WBG-II and MXene has promoted the crystallization ability of $\beta$-form and $\alpha$ form crystals, respectively. On the contrary, when WBG-II and MXene are both introduced, the crystallization temperature stops increasing but drops by $1.1^{\circ} \mathrm{C}$ comparing with that of iPP/WBG-II.

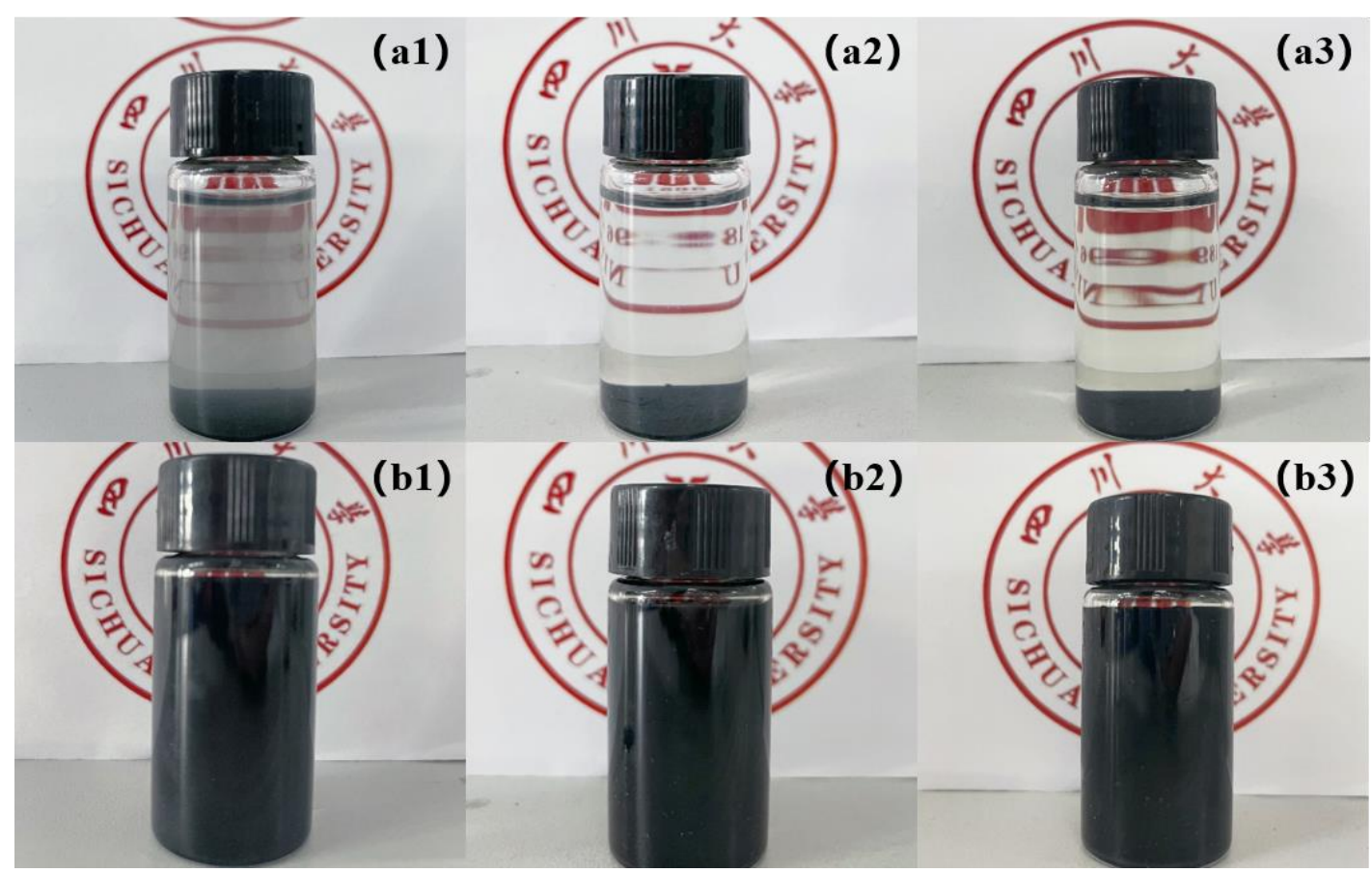

Figure 2. Digital photo of (a1-a3) $\mathrm{Ti}_{3} \mathrm{AlC}_{2}$ and (b1-b3) $\mathrm{Ti}_{3} \mathrm{C}_{2} \mathrm{~T}_{\mathrm{x}}$ dispersed in distilled water on day 1, day 3, and day 7 .
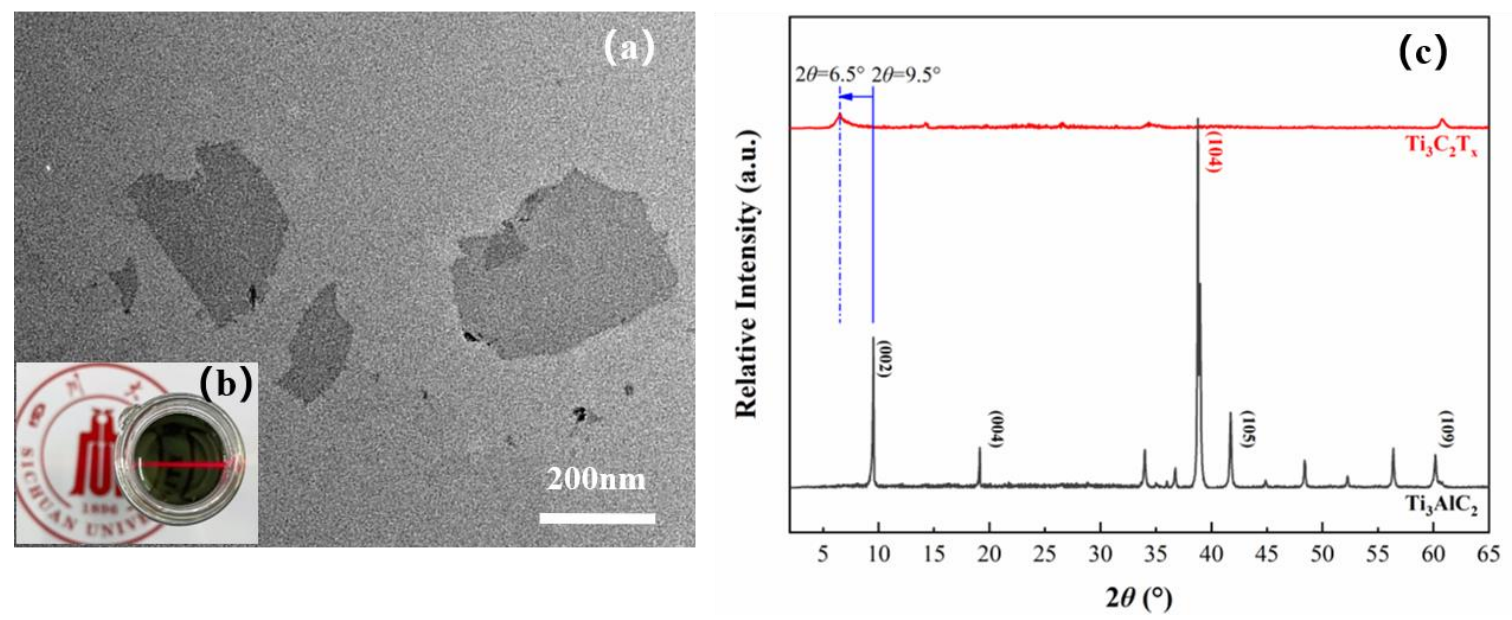

Figure 3. Analysis of $\mathrm{Ti}_{3} \mathrm{C}_{2} \mathrm{~T}_{\mathrm{x}}$ (a) TEM image of $\mathrm{Ti}_{3} \mathrm{C}_{2} \mathrm{~T}_{\mathrm{x}}$ dispersed in distilled water; (b) Digital photo of diluted $\mathrm{Ti}_{3} \mathrm{C}_{2} \mathrm{~T}_{\mathrm{x}}$ dispersion in distilled water under a red laser beam; (c) XRD pattern of $\mathrm{Ti}_{3} \mathrm{AlC}_{2}$ and $\mathrm{Ti}_{3} \mathrm{C}_{2} \mathrm{~T}_{\mathrm{x}}$. 


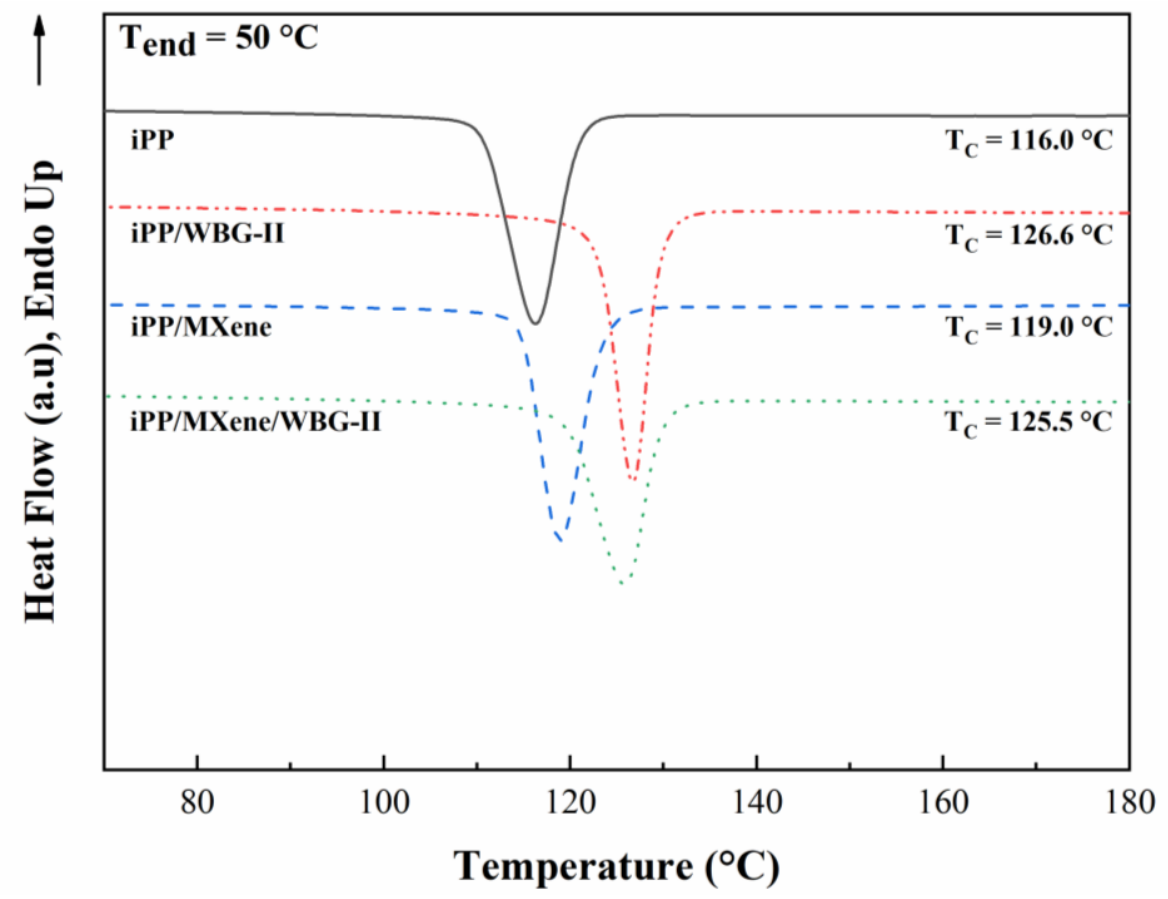

Figure 4. DSC cooling curve at the $\mathrm{T}_{\mathrm{end}}=50^{\circ} \mathrm{C}$.
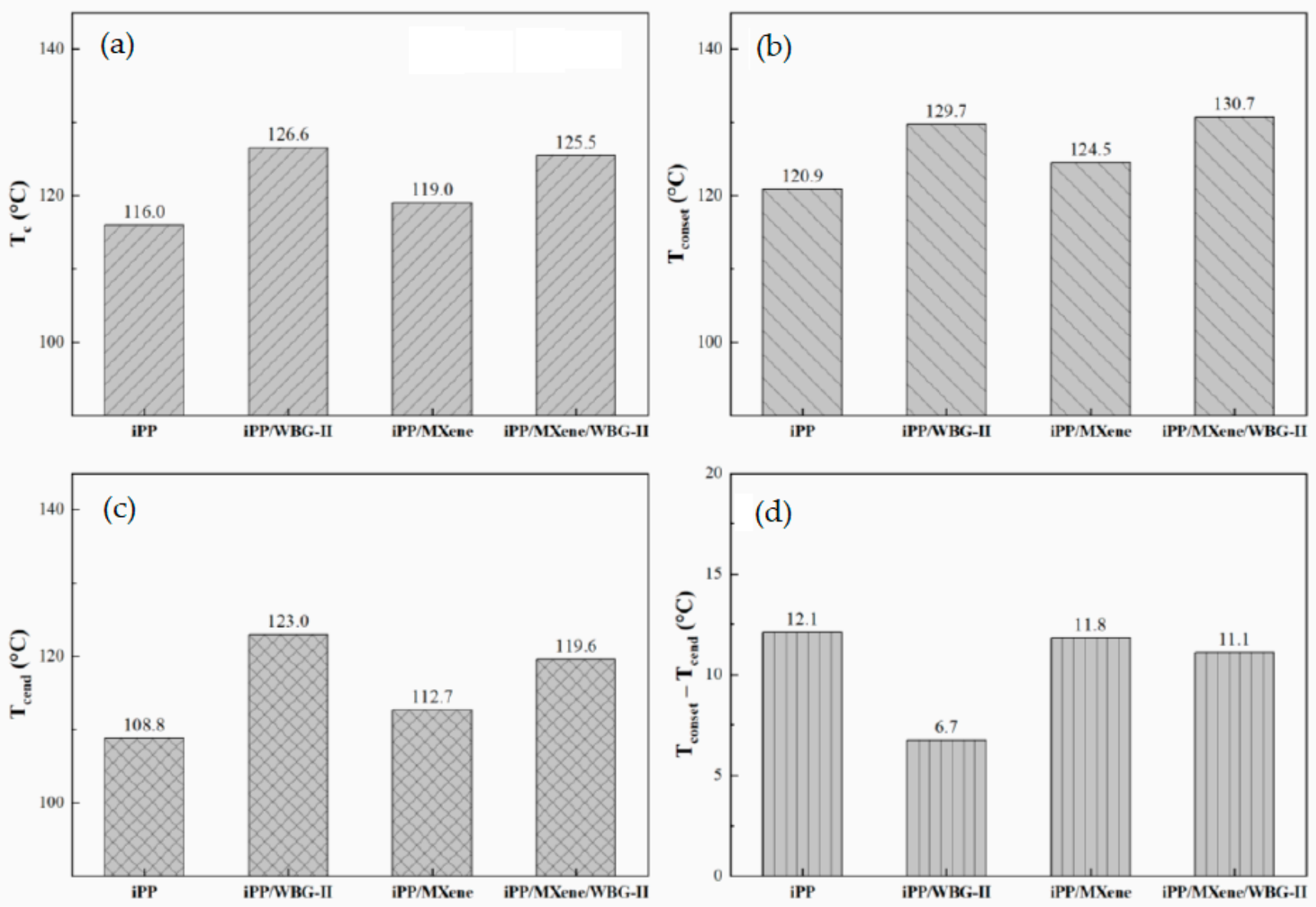

Figure 5. Plots of (a) $\mathrm{T}_{\mathrm{C}},(\mathbf{b}) \mathrm{T}_{\text {conset }},(\mathbf{c}) \mathrm{T}_{\text {cend }},(\mathbf{d}) \mathrm{T}_{\text {conset }}-\mathrm{T}_{\text {cend }}$ of four samples from the cooling curve at $\mathrm{T}_{\text {end }}=50^{\circ} \mathrm{C}$. 
To further understand the variation of crystallization temperatures, the nucleation efficiency of WBG-II and MXene as nucleating agents are evaluated via the following equation developed Fillon et al. [15,50]:

$$
\mathrm{NE}(\%)=\frac{\mathrm{T}_{\mathrm{cNA}}-\mathrm{T}_{\mathrm{c} 1}}{\mathrm{~T}_{\mathrm{c} 2 \max }-\mathrm{T}_{\mathrm{c} 1}} \times 100 \%
$$

where $T_{c N A}, T_{c 1}$, and $T_{c m a x}$ are the peak crystallization temperatures of nucleated, nonnucleated, and self-nucleated polymers. The NE is expressed as a percentage, where 100 stands for the highest efficiency and 0 stands for no nucleation behavior. Based on the work of Fillon et al. [50], the crystallization peak temperature of self-nucleated iPP is the highest and the value of $\mathrm{T}_{\mathrm{c} 2 \max }$ is taken as $140^{\circ} \mathrm{C}$. The calculated NE of WBG-II and MXene are plotted in Figure 6. It can be seen that the NE of WBG-II is evidently higher than MXene, which agrees well with the variation in $T_{c}$. Based on the previous studies $[15,16]$, a possible explanation in $\mathrm{T}_{\mathrm{c}}$ of four samples is proposed: while both WBG-II and MXene can work as $\beta$ and $\alpha$ nucleating agents, there exists a competitive relationship between them that would change the crystallization and polymorphic behavior of composites. According to the studies of Zhong et al. [16], WBG-II with higher NE might play the leading role in the system of iPP/MXene/WBG-II.

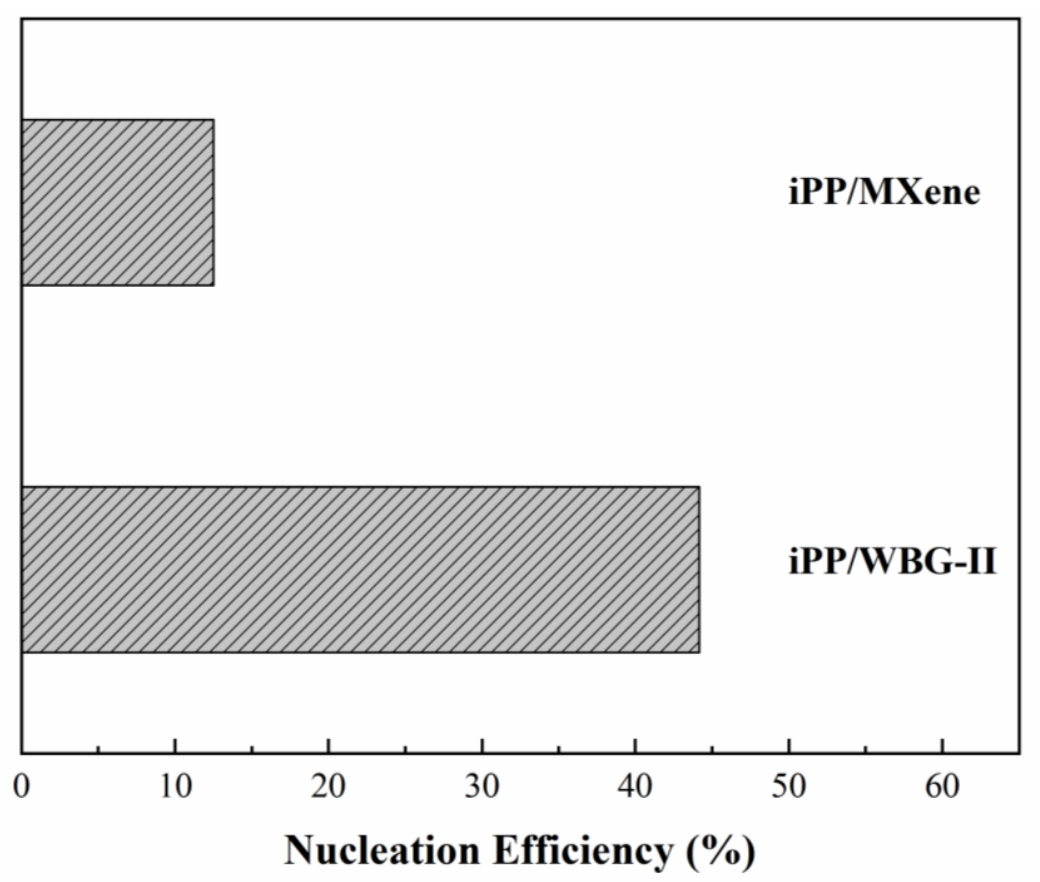

Figure 6. The plot of nucleation efficiencies (NEs) of iPP/WBG-II and iPP/MXene.

\subsection{Melting Behavior of $\beta$-iPP/MXene Composites}

The heating curves of four samples are plotted in Figure 7. Firstly, neat iPP and iPP/MXene only show one melting peak between $160-170{ }^{\circ} \mathrm{C}$, which represents the $\alpha$-from crystals in the structure. For iPP/WBG-II and iPP/MXene/WBG-II, two melting peaks are observed, of which the lower peak between $150-155^{\circ} \mathrm{C}$ corresponds to the $\beta$-form crystals. In addition, it can be observed from the heating curves that the $\beta$-peak in iPP/WBG-II is stronger than in $\mathrm{PP} / \mathrm{MXene} / \mathrm{WBG}-\mathrm{II}$. The relative content of $\beta$-crystals in two samples is calculated by Equation (1), and other parameters including peak melting temperature and degree of crystallinity are listed in Table 1 . The calculated results show that the relative percentage of $\beta$-phase $\left(\beta_{c}\right)$ of iPP/WBG-II is $7.4 \%$ higher than iPP/MXene/WBG-II so that $\alpha$-phase content is higher in iPP/MXene/WBG-II. Combined with the findings from crystallization curves, while both WBG-II and MXene promote the crystallization process, there might be competition between them. 


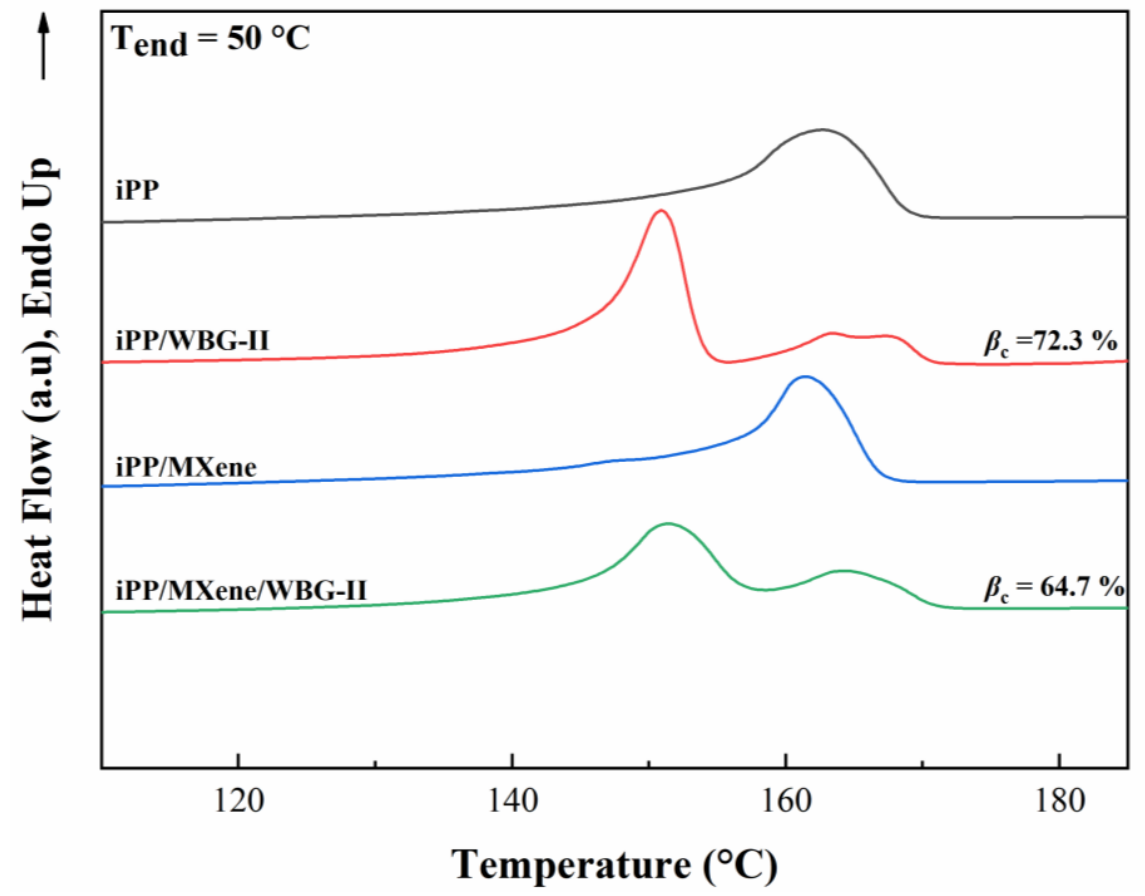

Figure 7. DSC heating curves of four samples.

Table 1. The heating curve parameters of four samples, where $T_{\mathrm{m} 1}$ and $\mathrm{T}_{\mathrm{m} 2}$ are the peak melting temperature of the $\alpha$ and $\beta$-phase, $X_{c}$ is the degree of crystallinity, $\alpha_{c}$ and $\beta_{c}$ are the relative percentage of $\alpha$ - and $\beta$-crystals, $X_{\alpha}$ and $X_{\beta}$ are the crystallinity of $\alpha$ - and $\beta$-crystals.

\begin{tabular}{cccccccc}
\hline Sample & $\begin{array}{c}\mathbf{T}_{\mathbf{m} 1} \\
\left({ }^{\circ} \mathbf{C}\right)\end{array}$ & $\begin{array}{c}\mathbf{T}_{\mathbf{m} 2} \\
\left({ }^{\circ} \mathbf{C}\right)\end{array}$ & $\begin{array}{c}\boldsymbol{X}_{\boldsymbol{c}} \\
\mathbf{( \% )}\end{array}$ & $\begin{array}{c}\boldsymbol{\alpha}_{\boldsymbol{c}} \\
\mathbf{( \% )}\end{array}$ & $\begin{array}{c}\boldsymbol{\beta}_{\boldsymbol{c}} \\
\mathbf{( \% )}\end{array}$ & $\begin{array}{c}\boldsymbol{X}_{\boldsymbol{\alpha}} \\
\mathbf{( \% )}\end{array}$ & $\begin{array}{c}\boldsymbol{X}_{\boldsymbol{\beta}} \\
\mathbf{( \% )}\end{array}$ \\
\hline iPP & 162.8 & - & 41.4 & - & - & - & - \\
iPP/WBG-II & 163.4 & 150.9 & 44.6 & 27.7 & 72.3 & 12.4 \\
iPP/MXene & 161.9 & - & 43.0 & - & - & - & 20.0 \\
$\mathrm{iPP} / \mathrm{MX}$ ene/WBG-II & 164.7 & 151.4 & 41.4 & 35.3 & 64.7 & - \\
\hline
\end{tabular}

Varga et al. [51,52] concluded that during the partial melting of $\beta$-crystals, $\beta$-iPP cooled down below critical temperature $\left(\mathrm{T}_{\text {end }}=100-105^{\circ} \mathrm{C}\right)$ will recrystallize into $\alpha$-iPP, leading to an increase in $\alpha$-phase content in the subsequent heating curve. Inversely, no $\beta \alpha$-recrystallization will occur if the $\beta$-iPP is not cooled below the critical temperature. To comparatively study the polymorphic behavior of iPP/WBG-II and iPP/MXene/WBGII and the thermal stability of the formed $\beta$-phase, an end temperature of cooling at $\mathrm{T}_{\text {end }}=100{ }^{\circ} \mathrm{C}$ was also chosen to compare the heating curves at $\mathrm{T}_{\text {end }}=50^{\circ} \mathrm{C}$. The heating curves of $\mathrm{T}_{\text {end }}=50^{\circ} \mathrm{C}$ and $\mathrm{T}_{\text {end }}=100{ }^{\circ} \mathrm{C}$ are plotted in Figure $8 \mathrm{a}, \mathrm{b}$, and two main trends can be observed from the curves.

Firstly, for both iPP/WBG-II and iPP/MXene/WBG-II, the $\alpha$-peaks at $\mathrm{T}_{\text {end }}=50^{\circ} \mathrm{C}$ appear stronger than at $\mathrm{T}_{\text {end }}=100{ }^{\circ} \mathrm{C}$, indicating that a certain amount of $\beta$-phase with less thermal stability transformed into $\alpha$-phase during the melting process when $\mathrm{T}_{\text {end }}=50^{\circ} \mathrm{C}$. Secondly, $\beta$-peaks of iPP/WBG-II at both end temperatures are higher than that of iPP/MXene/WBG-II. The values of $\beta_{c}$ are evaluated and listed in Figure 8. When $\mathrm{T}_{\text {end }}$ decreases from $100{ }^{\circ} \mathrm{C}$ to $50{ }^{\circ} \mathrm{C}$, the $\beta_{c}$ in iPP/WBG-II and iPP/MXene/WBG-II is decreased by $14.6 \%$ and $9.5 \%$. The decrease of $\beta_{c}$ corresponds to the $\beta$-phase with relatively low thermal stability, which transformed into $\alpha$-phase via $\beta \alpha$-recrystallization during the melting process. To be more exact, the larger the $\beta_{c}$ difference between $\mathrm{T}_{\text {end }}=50^{\circ} \mathrm{C}$ and $\mathrm{T}_{\mathrm{end}}=100^{\circ} \mathrm{C}$, the higher the fraction of $\beta$-phase with relatively low thermal stability. Meanwhile, the higher the $\beta_{c}$ at $\mathrm{T}_{\text {end }}=100{ }^{\circ} \mathrm{C}$, the stronger ability for the sample to form $\beta$-phase. Therefore, the results of Figure 7 reveal that the addition of MXene into $\beta$-iPP 
decreases the total amount of formed $\beta$-phase but increases the thermal stability of the formed $\beta$-phase as well, which might be attributed to the competitive effects between $\beta$-NA and MXene.
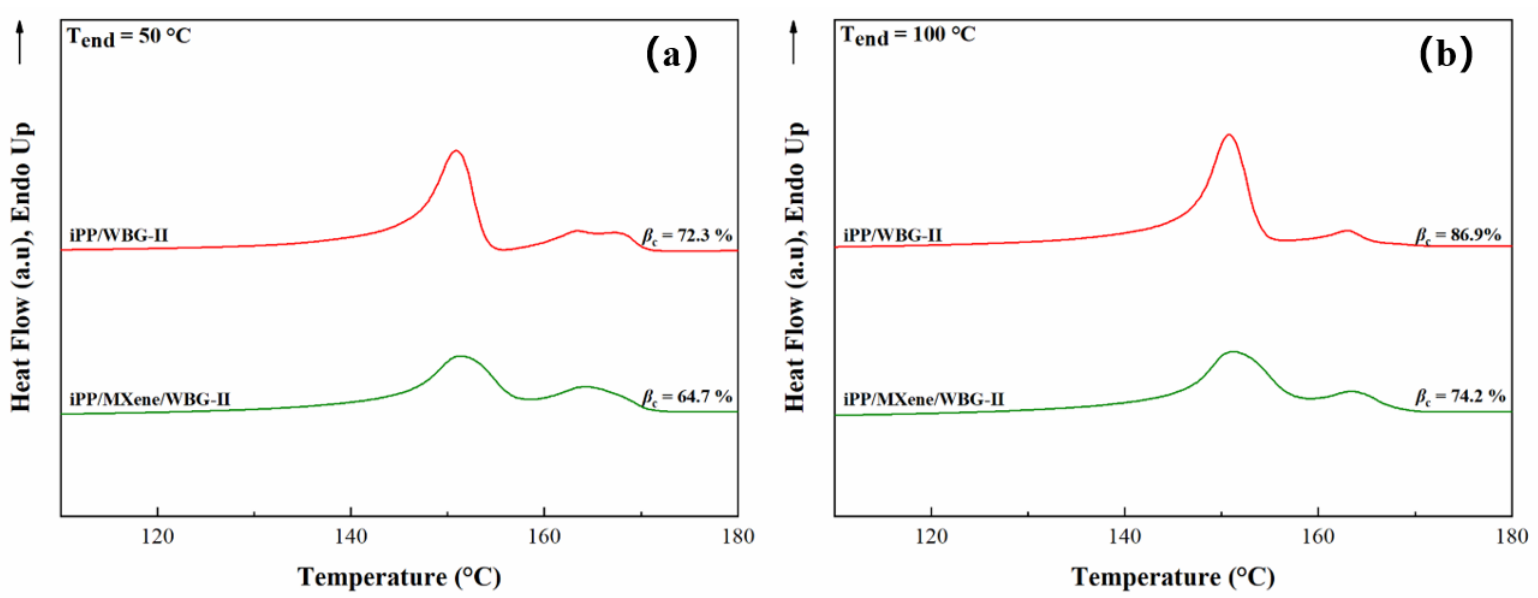

Figure 8. DSC heating curves of iPP/WBG-II and iPP/MXene/WBG-II at (a) $\mathrm{T}_{\text {end }}=50^{\circ} \mathrm{C}$ and (b) $\mathrm{T}_{\text {end }}=100^{\circ} \mathrm{C}$.

\subsection{WAXD Analysis}

The WAXD results of the four samples are shown in Figure 9, and the calculated crystalline structure parameters, including the $2 \theta, d$-spacing, line width at half maximum (FWHM) in radians and crystallite sizes $L$ of each peak, are listed in Table 2.

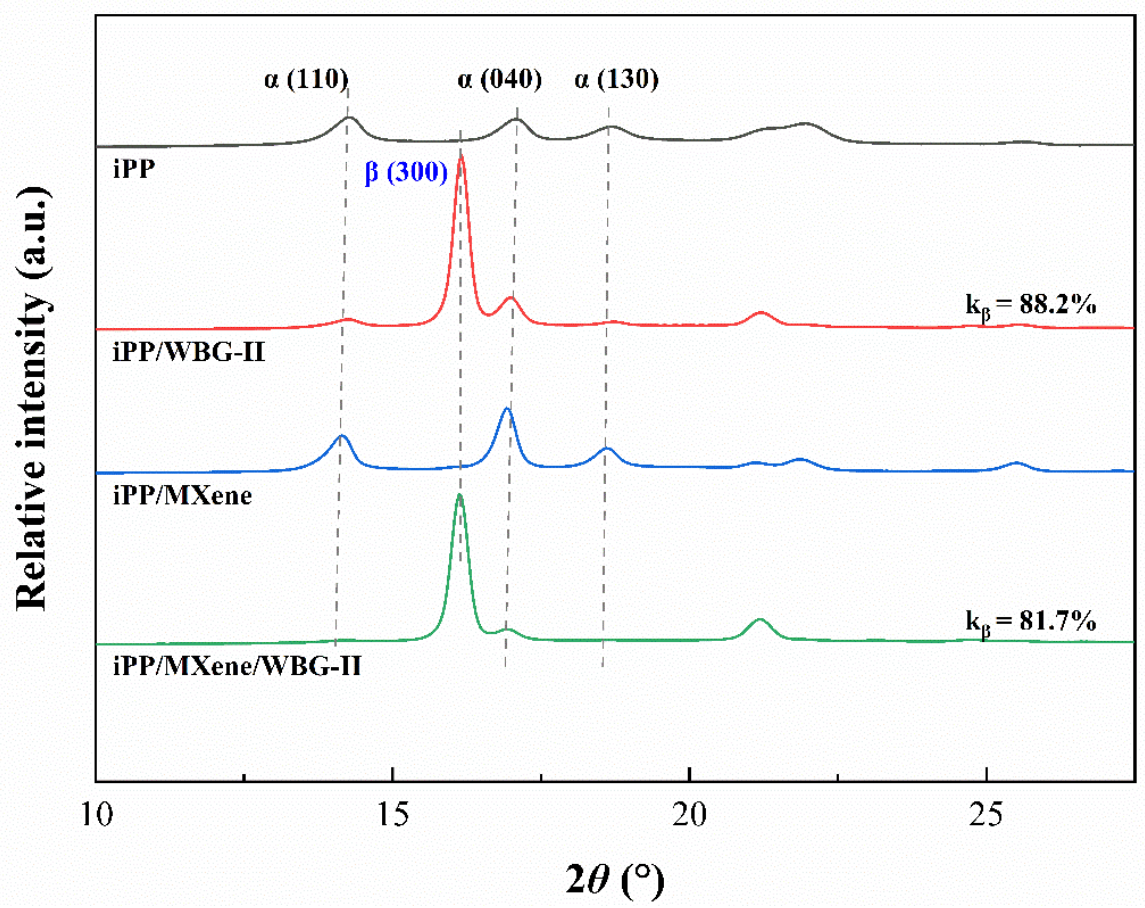

Figure 9. WAXD patterns of four samples. 
Table 2. WAXD parameters of four samples.

\begin{tabular}{|c|c|c|c|c|c|}
\hline \multirow{2}{*}{ Parameters } & \multirow{2}{*}{ Sample } & \multicolumn{4}{|c|}{$(h k l)$} \\
\hline & & $\alpha(110)$ & $\alpha(040)$ & $\alpha(130)$ & $\beta(300)$ \\
\hline \multirow{4}{*}{$2 \theta\left(^{\circ}\right)$} & iPP & 14.2 & 17.1 & 18.6 & - \\
\hline & $\mathrm{iPP} / \mathrm{WBG}-\mathrm{II}$ & 14.3 & 16.9 & 18.6 & 16.1 \\
\hline & iPP/MXene & 14.1 & 16.9 & 18.6 & - \\
\hline & iPP/MXene/WBG-II & 14.3 & 17.0 & 18.7 & 16.2 \\
\hline \multirow{4}{*}{$\begin{array}{c}d \text {-spacing } \\
(\AA)\end{array}$} & iPP & 6.2 & 5.2 & 4.8 & - \\
\hline & iPP/WBG-II & 6.2 & 5.2 & 4.8 & 5.5 \\
\hline & iPP/MXene & 6.3 & 5.2 & 4.8 & - \\
\hline & iPP/MXene/WBG-II & 6.2 & 5.2 & 4.7 & 5.5 \\
\hline \multirow{4}{*}{ FWHM } & iPP & 0.7 & 0.6 & 0.9 & - \\
\hline & iPP/WBG-II & 0.7 & 0.7 & 1.2 & 0.3 \\
\hline & iPP/MXene & 0.5 & 0.4 & 0.5 & - \\
\hline & iPP/MXene/WBG-II & 0.6 & 0.5 & 0.5 & 0.3 \\
\hline \multirow{4}{*}{$L(\mathrm{~nm})$} & iPP & 12.1 & 12.7 & 8.5 & - \\
\hline & iPP/WBG-II & 11.1 & 12.2 & 6.6 & 24.5 \\
\hline & iPP/MXene & 16.1 & 20.5 & 17.7 & - \\
\hline & iPP/MXene/WBG-II & 13.1 & 15.1 & 15.6 & 27.1 \\
\hline
\end{tabular}

For neat iPP and iPP/MXene, the three strongest peaks are found at around $14.1^{\circ}, 16.9^{\circ}$, and $18.6^{\circ}$ corresponding to $\alpha(110), \alpha(040)$, and $\alpha$ (130) diffractions of $\alpha$-crystal [11,53]. For iPP/WBG-II and iPP/MXene/WBG-II, a peak around $16.1^{\circ}$ corresponding to $\beta$ (300) diffraction peak, indicating the existence of $\beta$-crystals in their structure. The relative content of $\beta$-crystal in iPP/WBG-II and iPP/MXene/WBG-II are $k_{\beta}=88.2 \%$ and $81.7 \%$, respectively. This result is in good agreement with the variation of $\beta_{c}$ in Figure 8. Both results denote that when MXene is added in $\beta$-PP, the $\beta$-phase content would decrease due to competition between $\alpha$-nucleation effect of MXene and $\beta$-nucleation effect of WBG-II. Moreover, Table 2 reveals that the addition of MXene into neat iPP greatly increases the crystallite sizes $L$ of the sample, while the addition of WBG-II into neat iPP decreases the $L$. When both WBG-II and MXene are added, an increase of $L$ can be observed.

\subsection{PLOM Observation}

Based on the crystallization behaviors in Figure 4 and WAXD results in Figure 9, it could be observed that neat iPP and iPP/MXene show similar Tc and contain only $\alpha$-phase.

Moreover, the Tc of iPP/WBG-II and iPP/MXene/WBG-II only differ by around $1{ }^{\circ} \mathrm{C}$ and they both contain $\beta$-phase. To conveniently compare the evolution of hierarchical crystalline morphologies, the samples were isothermally crystallized at the same temperature and discussed by two groups (neat iPP and iPP/MXene; iPP/WBG-II and iPP/MXene/WBG-II).

From Figure 10a,b, it can be seen that $\alpha$-crystal spherulites exist in iPP and iPP/MXene, but the crystallization of these two samples is quite different. For neat iPP, the crystal nuclei start to appear after $5 \mathrm{~min}$ from crystallization and continue to grow. After $15 \mathrm{~min}$ from crystallization, the number of nuclei did not increase evidently, while the spherulite size continues to increase. After $30 \mathrm{~min}$, the spherulites continue to grow in size, the crystallization is yet to complete. On the contrary, for iPP/MXene, a large number of crystal nuclei occur in the field of view after $5 \mathrm{~min}$ from crystallization but the growth rate might be relatively slow. The PLOM images stay almost unchanged after $15 \mathrm{~min}$, indicating that the crystallization is finished. Comparing iPP/MXene with neat iPP, the crystal nuclei appear much earlier with significantly higher nucleation density. However, the growth rate of nuclei seems to be slower, the crystallite size of iPP/MXene is much smaller. Under the same isothermal crystallization condition, the findings suggest that the NE of iPP/MXene is evidently higher than neat iPP, which is in accord with the DSC results above. 
Figure 10c,d show that $\beta$-crystals exist in iPP/WBG-II and iPP/MXene/WBG-II. For $\mathrm{iPP} / \mathrm{WBG}-\mathrm{II}$, the nuclei occur in the field of view 2 min after crystallization starts and continue to grow, reflecting the strong nucleation effect of WBG-II. The PLOM image stays almost unchanged but becomes brighter after $3 \mathrm{~min}$, and the crystallization finishes at 5 min. To identify $\beta$-crystals from the morphology, the sample was selectively melted at $156{ }^{\circ} \mathrm{C}$ to so that the residual $\alpha$-crystals could be observed [54]. The result indicates that most area of the screen is occupied with the highlighted $\beta$-crystals. However, only a few nuclei were formed after $3 \mathrm{~min}$ from crystallization in the case of iPP/MXene/WBG-II, indicating that $\mathrm{PP} / \mathrm{WBG}-\mathrm{II}$ has a much higher NE at the early stage of crystallization. The PLOM image of iPP/MXene/WBG-II shows that $\beta$-crystals dominate in the morphology, which is consistent with the assumption that WBG-II plays a leading role in determining the behavior in the system. However, due to the competitive nucleation effects of WBG-II and MXene, less area of highlighted $\beta$-crystals can be seen from Figure 10d.

$\mathbf{t}=\mathbf{0} \min$

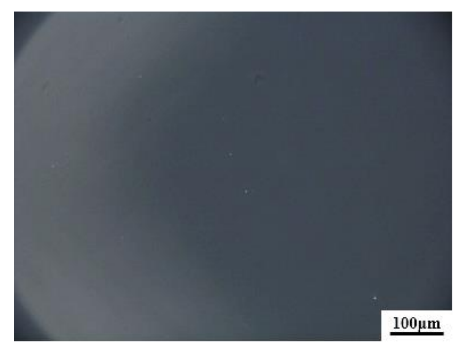

$t=15 \min$

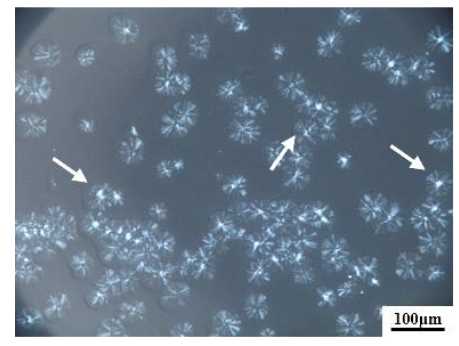

$t=0$ min

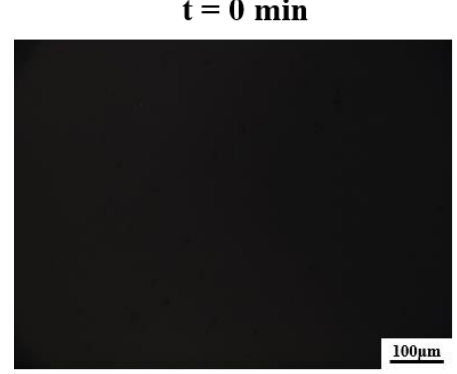

$t=15 \mathrm{~min}$

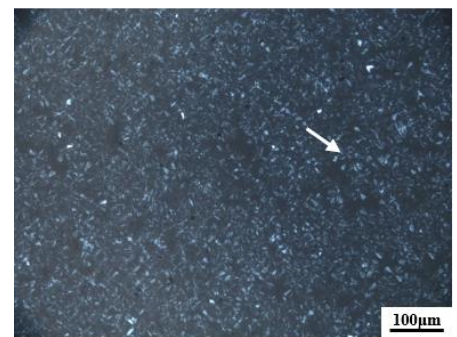

$t=5$ min

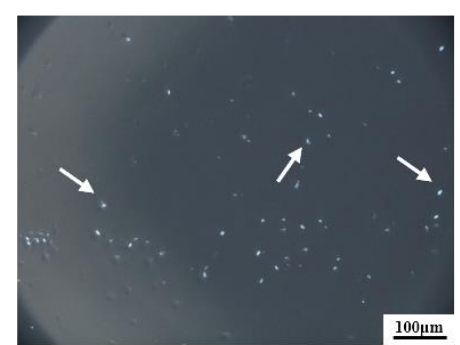

$\mathbf{t}=\mathbf{2 0} \mathrm{min}$

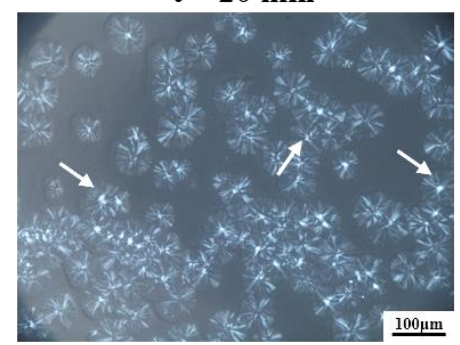

(a) Neat iPP

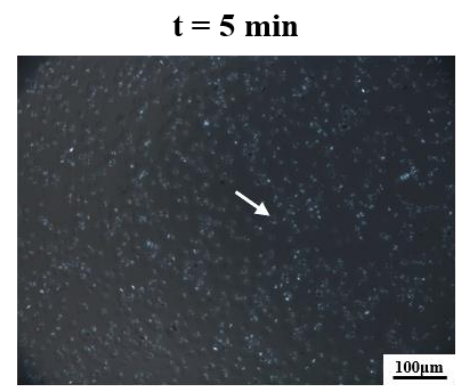

$t=20 \mathrm{~min}$

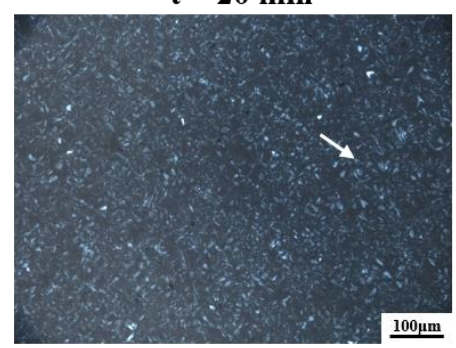

(b) iPP/MXene $t=10 \mathrm{~min}$

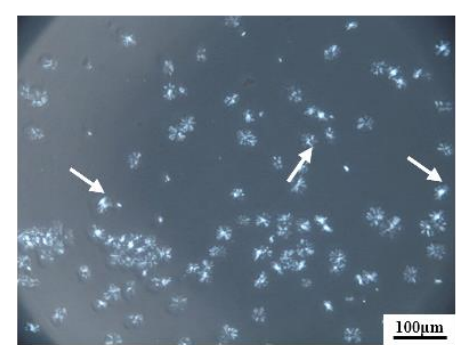

$\mathbf{t}=30 \mathrm{~min}$

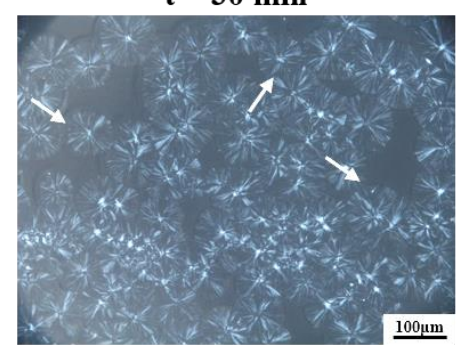

$t=10 \mathrm{~min}$

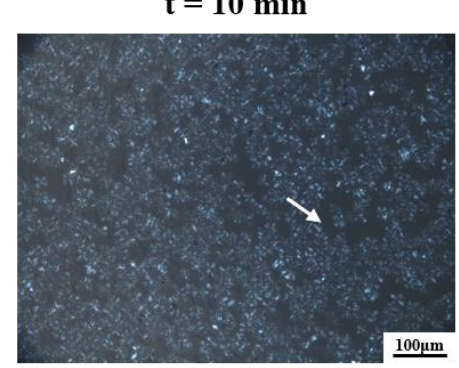

$t=30 \mathrm{~min}$

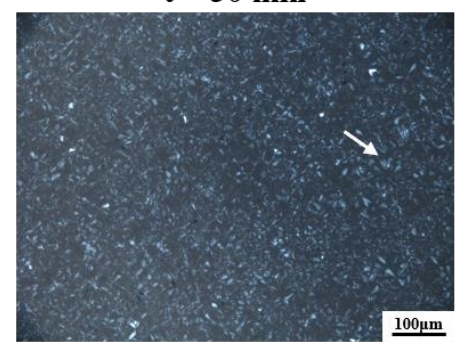

Figure 10. Cont. 


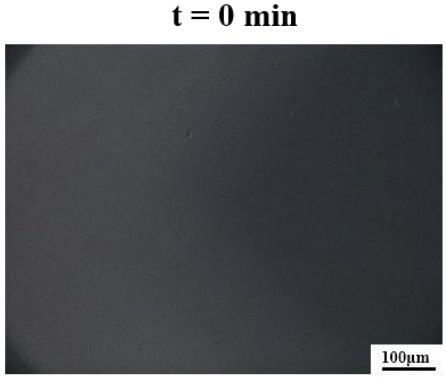

$\mathrm{t}=\mathbf{3}$ min

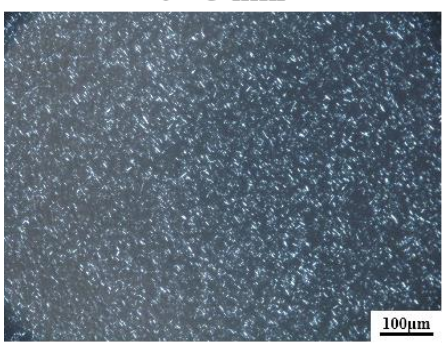

$\mathrm{t}=\mathbf{0} \mathrm{min}$

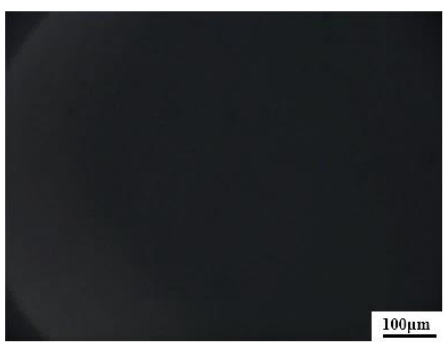

$\mathrm{t}=3 \mathrm{~min}$

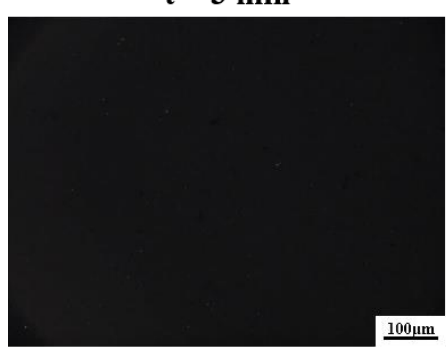

$\mathbf{t}=\mathbf{1} \min$

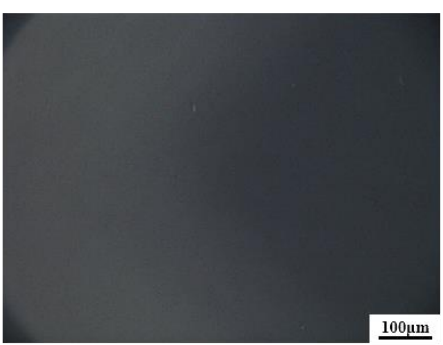

$\mathrm{t}=\mathbf{5} \mathrm{min}$

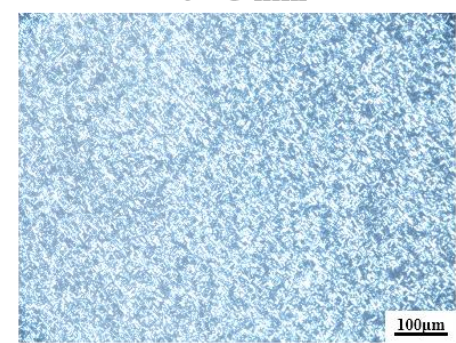

(c) $\mathrm{iPP} / \mathrm{WBG}-\mathrm{II}$

$\mathrm{t}=1 \mathrm{~min}$

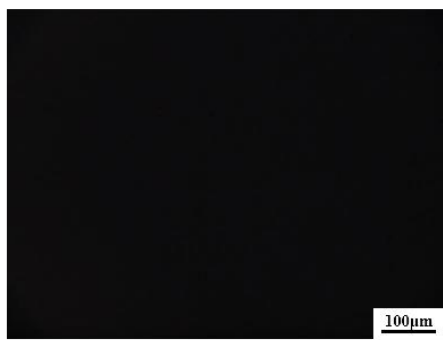

$\mathbf{t}=\mathbf{5} \mathrm{min}$

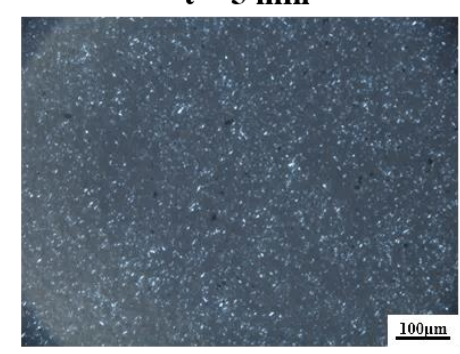

(d) iPP/MXene/WBG-II
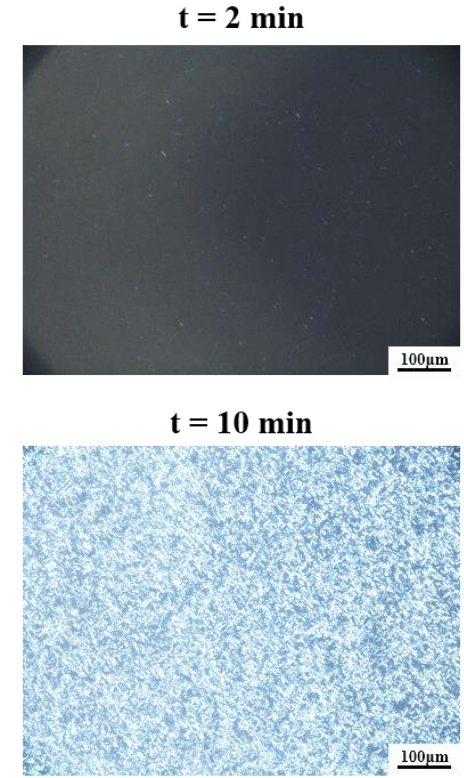

$\mathbf{t}=\mathbf{2}$ min

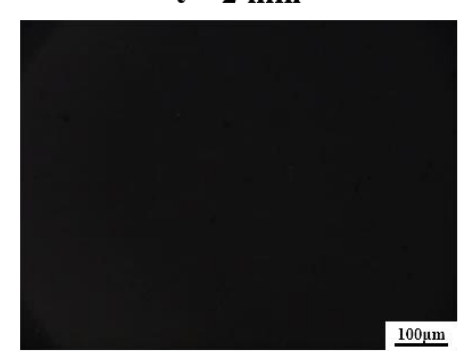

$\mathrm{t}=10 \mathrm{~min}$

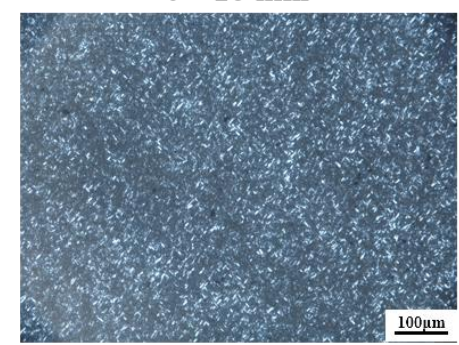

Figure 10. Crystallization morphological evolution during isothermal crystallization of (a) neat iPP (b) iPP/MXene (c) iPP/WBG-II and (d) iPP/MXene/WBG-II at $140{ }^{\circ} \mathrm{C}$. The bar represents $100 \mu \mathrm{m}$.

The PLOM images agree well with the previous DSC and WAXD analysis. When MXene is introduced into iPP, the crystallization process is promoted which might be caused by more nucleation sites. On the contrary, the introduction of MXene into iPP/WBG-II slows down the crystallization process due to the competition between MXene and WBG-II, and greatly changes the polymorphic behavior of the composites.

\section{Conclusions}

In this work, iPP was mixed with a commonly used MXene, $\mathrm{Ti}_{3} \mathrm{C}_{2} \mathrm{~T}_{\mathrm{x}}$, and the $\beta$ nucleating agent WBG-II to prepare samples with different compositions. The effects of MXene on the crystallization and polymorphic behavior of $\beta$-nucleated iPP were then comparatively studied. The DSC cooling curves indicated that MXene and WBG-II promote the crystallization ability of $\alpha$ - and $\beta$-form crystals, respectively, but the nucleation efficiency 
of WBG-II is higher. DSC heating curves and WAXD results showed that $\beta$-phase content in iPP/WBG-II is higher than iPP/MXene/WBG-II. These results suggest that a competitive relationship exists between MXene and WBG-II as $\alpha$ and $\beta$ nucleating agents, and WBG-II plays a leading role in determining the crystallization of iPP nucleated with both MXene and WBG-II. To investigate the thermal stability of $\beta$-phase, $\beta$-iPP samples were cooled to two end temperatures $\left(50^{\circ} \mathrm{C}\right.$ and $100^{\circ} \mathrm{C}$ ), and the resulting heating curves were compared. The results indicated that the $\beta$-phase is thermally metastable and would transform to the $\alpha$ phase when cooling below a critical temperature. The online PLOM results agree well with others indicating that both MXene and WBG-II improves the crystallization process of iPP and WBG-II dominates in the crystalline morphology of iPP.

Author Contributions: Conceptualization, W.P. and J.K.; methodology, W.P. and Y.Z.; software, W.P. and Y.Z.; validation, W.P., B.H. and Y.C.; formal analysis, W.P.; investigation, B.H.; resources, X.S.; data curation, W.P.; writing-original draft preparation, W.P.; writing-review and editing, W.P. and X.S.; visualization, M.X.; supervision, X.S.; project administration, J.K. and X.S.; funding acquisition, J.K. All authors have read and agreed to the published version of the manuscript.

Funding: This research was funded by National Natural Science Foundation of China (NSFC, Grant Nos. 51503134, 51702282) and State Key Laboratory of Polymer Materials Engineering (Grant No. SKLPME 2017-3-02), and the APC was funded by National Natural Science Foundation of China (NSFC, Grant No. 51702282).

Institutional Review Board Statement: Not applicable.

Informed Consent Statement: Not applicable.

Data Availability Statement: Not applicable.

Acknowledgments: We are grateful to the Analytical and Testing Center of Sichuan University for providing WAXD and TEM measurement.

Conflicts of Interest: There are no conflict of interest to declare.

\section{References}

1. Luo, S.; Wei, L.; Sun, J.; Huang, A.; Qin, S.; Luo, H.; Gao, C.; Zheng, Y.; Shen, J. Crystallization behavior and optical properties of isotactic polypropylene filled with $\alpha$-nucleating agents of multilayered distribution. RSC Adv. 2020, 10, 387-393. [CrossRef]

2. $\quad$ Krache, R.; Benavente, R.; López-Majada, J.; Perea, J.M.; Pérez, E. Competition between $\alpha$, $\beta$, and $\gamma$ Polymorphs in a $\beta$-Nucleated Metallocenic Isotactic Polypropylene. Macromolecules 2007, 40, 6871-6878. [CrossRef]

3. Jiang, X.; Fang, Y.; Yu, Y.; Kang, J.; Cao, Y.; Xiang, M.; Li, L.; Sheng, X.; Hao, Z. Exploring the Effects of Stereo-Defect Distribution on Nonisothermal Crystallization and Melting Behavior of beta-Nucleated Isotactic Polypropylene/Graphene Oxide Composites. ACS Omega 2019, 4, 3020-3028. [CrossRef] [PubMed]

4. Xu, R.; Xu, G.; Wang, J.; Chen, J.; Yang, F.; Kang, J.; Xiang, M. Influence of L-lysine on the permeation and antifouling performance of polyamide thin film composite reverse osmosis membranes. RSC Adv. 2018, 8, 25236-25247. [CrossRef]

5. Bruckner, S.; Meille, S.V.; Petraccone, V.; Pirozzi, B. Polymorphism in isotactic polypropylene. Prog. Polym. Sci. 1991, 16, 361-404. [CrossRef]

6. Varga, J. Supermolecular structure of isotactic polypropylene. J. Mater. Sci. 1992, 27, 2557-2579. [CrossRef]

7. Zhang, N.; Zhang, Q.; Wang, K.; Deng, H.; Fu, Q. Combined effect of $\beta$-nucleating agent and multi-walled carbon nanotubes on polymorphic composition and morphology of isotactic polypropylene. J. Therm. Anal. Calorim. 2011, 107, 733-743. [CrossRef]

8. Pawlak, A.; Piorkowska, E. Crystallization of isotactic polypropylene in a temperature gradient. Colloid Polym. Sci. 2001, 279, 939-946. [CrossRef]

9. Zhang, B.; Chen, J.; Ji, F.; Zhang, X.; Zheng, G.; Shen, C. Effects of melt structure on shear-induced $\beta$-cylindrites of isotactic polypropylene. Polymer 2012, 53, 1791-1800. [CrossRef]

10. Li, H.; Sun, X.; Yan, S.; Schultz, J.M. Initial Stage of iPP $\beta$ to $\alpha$ Growth Transition Induced by Stepwise Crystallization. Macromolecules 2008, 41, 5062-5064. [CrossRef]

11. Varga, J.; Mudra, I.; Ehrenstein, G.W. Highly active thermally stable $\beta$-nucleating agents for isotactic polypropylene. J. Appl. Polym. Sci. 1999, 74, 2357-2368. [CrossRef]

12. Varga, J. $\beta$-Modification of Isotactic Polypropylene: Preparation, Structure, Processing, Properties, and Application. J. Macromol. Sci. Part B 2007, 41, 1121-1171. [CrossRef]

13. Luo, F.; Geng, C.; Wang, K.; Deng, H.; Chen, F.; Fu, Q.; Na, B. New Understanding in Tuning Toughness of $\beta$-Polypropylene: The Role of $\beta$-Nucleated Crystalline Morphology. Macromolecules 2009, 42, 9325-9331. [CrossRef] 
14. Wang, S.-W.; Yang, W.; Bao, R.-Y.; Wang, B.; Xie, B.-H.; Yang, M.-B. The enhanced nucleating ability of carbon nanotube-supported $\beta$-nucleating agent in isotactic polypropylene. Colloid Polym. Sci. 2010, 288, 681-688. [CrossRef]

15. Kang, J.; He, J.; Chen, Z.; Yu, H.; Chen, J.; Yang, F.; Cao, Y.; Xiang, M. Investigation on the crystallization behavior and polymorphic composition of isotactic polypropylene/multi-walled carbon nanotube composites nucleated with $\beta$-nucleating agent. J. Therm. Anal. Calorim. 2014, 119, 1769-1780. [CrossRef]

16. Zhao, S.; Xin, Z. Nucleation characteristics of the $\alpha / \beta$ compounded nucleating agents and their influences on crystallization behavior and mechanical properties of isotactic polypropylene. J. Polym. Sci. Part B Polym. Phys. 2010, 48, 653-665. [CrossRef]

17. Riazi, H.; Anayee, M.; Hantanasirisakul, K.; Shamsabadi, A.A.; Anasori, B.; Gogotsi, Y.; Soroush, M. Surface Modification of a MXene by an Aminosilane Coupling Agent. Adv. Mater. Interfaces 2020, 7, 1902008. [CrossRef]

18. Naguib, M.; Kurtoglu, M.; Presser, V.; Lu, J.; Niu, J.; Heon, M.; Hultman, L.; Gogotsi, Y.; Barsoum, M.W. Two-dimensional nanocrystals produced by exfoliation of Ti3 AlC2. Adv. Mater 2011, 23, 4248-4253. [CrossRef] [PubMed]

19. Verger, L.; Xu, C.; Natu, V.; Cheng, H.-M.; Ren, W.; Barsoum, M.W. Overview of the synthesis of MXenes and other ultrathin 2D transition metal carbides and nitrides. Curr. Opin. Solid State Mater. Sci. 2019, 23, 149-163. [CrossRef]

20. Gogotsi, Y.; Anasori, B. The Rise of MXenes. ACS Nano 2019, 13, 8491-8494. [CrossRef]

21. Naguib, M.; Come, J.; Dyatkin, B.; Presser, V.; Taberna, P.-L.; Simon, P.; Barsoum, M.W.; Gogotsi, Y. MXene: A promising transition metal carbide anode for lithium-ion batteries. Electrochem. Commun. 2012, 16, 61-64. [CrossRef]

22. Verger, L.; Natu, V.; Carey, M.; Barsoum, M.W. MXenes: An Introduction of Their Synthesis, Select Properties, and Applications Trends Chem. 2019, 1, 656-669. [CrossRef]

23. Ling, Z.; Ren, C.E.; Zhao, M.Q.; Yang, J.; Giammarco, J.M.; Qiu, J.; Barsoum, M.W.; Gogotsi, Y. Flexible and conductive MXene films and nanocomposites with high capacitance. Proc. Natl. Acad. Sci. USA 2014, 111, 16676-16681. [CrossRef] [PubMed]

24. Zhang, H.; Wang, L.; Chen, Q.; Li, P.; Zhou, A.; Cao, X.; Hu, Q. Preparation, mechanical and anti-friction performance of MXene/polymer composites. Mater. Des. 2016, 92, 682-689. [CrossRef]

25. Shi, Y.; Liu, C.; Liu, L.; Fu, L.; Yu, B.; Lv, Y.; Yang, F.; Song, P. Strengthening, toughing and thermally stable ultra-thin MXene nanosheets / polypropylene nanocomposites via nanoconfinement. Chem. Eng. J. 2019, 378. [CrossRef]

26. Cao, X.; Wu, M.; Zhou, A.; Wang, Y.; He, X.; Wang, L. Non-isothermal crystallization and thermal degradation kinetics of MXene/linear low-density polyethylene nanocomposites. e-Polymers 2017, 17, 373-381. [CrossRef]

27. Peng, W.; Hu, R.; Jiang, W.; Kang, J.; Xiang, M. Effects of MXene on Nonisothermal Crystallization Kinetics of Isotactic Polypropylene. ACS Omega 2021, 6, 19973-19982. [CrossRef]

28. Xu, R.; Wang, J.; Chen, D.; Liu, T.; Zheng, Z.; Yang, F.; Chen, J.; Kang, J.; Cao, Y.; Xiang, M. Preparation and performance of a charge-mosaic nanofiltration membrane with novel salt concentration sensitivity for the separation of salts and dyes. J. Membr. Sci. 2020, 595, 117472. [CrossRef]

29. Li, Y.; Liu, H.; Huang, X.; Song, X.; Kang, J.; Chen, Z.; Zeng, F.; Chen, J. Investigation on the Roles of $\beta$-Nucleating Agents in Crystallization and Polymorphic Behavior of Isotactic Polypropylene. Polym. Sci. Ser. A 2020, 62, 470-480. [CrossRef]

30. Yu, Y.; Xu, R.; Chen, J.; Kang, J.; Xiang, M.; Li, Y.; Li, L.; Sheng, X. Ordered structure effects on $\beta$-nucleated isotactic polypropylene/graphene oxide composites with different thermal histories. RSC Adv. 2019, 9, 19630-19640. [CrossRef]

31. Yu, Y.; Zeng, F.; Chen, J.; Kang, J.; Yang, F.; Cao, Y.; Xiang, M. Regulating polycrystalline behavior of the $\beta$-nucleated isotactic polypropylene/graphene oxide composites by melt memory effect. Polym. Compos. 2018, 40, E440-E448. [CrossRef]

32. Yu, Y.; Zeng, F.; Chen, J.; Kang, J.; Yang, F.; Cao, Y.; Xiang, M. Isothermal crystallization kinetics and subsequent melting behavior of $\beta$-nucleated isotactic polypropylene/graphene oxide composites with different ordered structure. Polym. Int. 2018, 67, 1212-1220. [CrossRef]

33. Zeng, F.; Chen, J.; Yang, F.; Kang, J.; Cao, Y.; Xiang, M. Effects of Polypropylene Orientation on Mechanical and Heat Seal Properties of Polymer-Aluminum-Polymer Composite Films for Pouch Lithium-Ion Batteries. Materials 2018, 11, 144. [CrossRef] [PubMed]

34. Yu, Y.; Zeng, F.; Chen, J.; Kang, J.; Yang, F.; Cao, Y.; Xiang, M. Effects of ordered structure on non-isothermal crystallization kinetics and subsequent melting behavior of $\beta$-nucleated isotactic polypropylene/graphene oxide composites. J. Therm. Anal. Calorim. 2019, 136, 1667-1678. [CrossRef]

35. Kang, J.; Weng, G.; Chen, Z.; Chen, J.; Cao, Y.; Yang, F.; Xiang, M. New understanding in the influence of melt structure and $\beta$-nucleating agents on the polymorphic behavior of isotactic polypropylene. RSC Adv. 2014, 56, 29514-29526. [CrossRef]

36. Kang, J.; Gai, J.; Li, J.; Chen, S.; Peng, H.; Wang, B.; Cao, Y.; Li, H.; Chen, J.; Yang, F.; et al. Dynamic crystallization and melting behavior of $\beta$-nucleated isotactic polypropylene polymerized with different Ziegler-Natta catalysts. J. Polym. Res. 2013, 20, 70. [CrossRef]

37. Jiang, W.; Song, Y.; Song, X.; Zhang, Y.; Xiang, M. Influences of Molecular Structure on the Non-Isothermal Crystallization Behavior of $\beta$-Nucleated Isotactic Polypropylene. Polym. Sci. Ser. A 2020, 62, 616-629. [CrossRef]

38. Wang, J.; Zhang, S.; Liu, Q.; Du, S.; Guo, Y.C.; Zheng, N.; Wang, F.Y. Conditional Uncorrelation and Efficient Subset Selection in Sparse Regression. IEEE Trans. Cybern. 2021, 1-10. [CrossRef]

39. Wang, J.; Zheng, N.; Chen, B.; Chen, P.; Chen, S.; Liu, Z.; Wang, F.; Xi, B. Multivariate Correlation Entropy and Law Discovery in Large Data Sets. IEEE Intell. Syst. 2018, 33, 47-54. [CrossRef]

40. Jones, A.T.; Aizlewood, J.M.; Beckett, D.R. Crystalline Forms of Isotactic Polypropylene. Macromol. Chem. Phys. 1964, 75, 134-158. [CrossRef] 
41. Kang, J.; Chen, D.; Xiong, B.; Zheng, N.; Yang, F.; Xiang, M.; Zheng, Z. A facile route for the fabrication of polypropylene separators for lithium ion batteries with high elongation and strong puncture resistance. Ind. Eng. Chem. Res. 2019, 58, 23135-23142. [CrossRef]

42. Zhang, F.; Jiang, W.; Song, X.; Kang, J.; Cao, Y.; Xiang, M. Effects of Hyperbranched Polyester-Modified Carbon Nanotubes on the Crystallization Kinetics of Polylactic Acid. ACS Omega 2021, 6, 10362-10370. [CrossRef] [PubMed]

43. Zeng, F.; Xu, R.; Ye, L.; Xiong, B.; Kang, J.; Xiang, M.; Li, L.; Sheng, X.; Hao, Z. Effects of heat setting on the morphology and performances of polypropylene separator for lithium ion batteries. Ind. Eng. Chem. Res. 2019, 58, 2217-2224. [CrossRef]

44. Yu, Y.; Xiong, B.; Zeng, F.; Xu, R.; Yang, F.; Kang, J.; Xiang, M.; Li, L.; Sheng, X.; Hao, Z. Influences of Compression on the Mechanical Behavior and Electrochemical Performances of Separators for Lithium Ion Batteries. Ind. Eng. Chem. Res. 2018, 57, 17142-17151. [CrossRef]

45. Alhabeb, M.; Maleski, K.; Anasori, B.; Lelyukh, P.; Clark, L.; Sin, S.; Gogotsi, Y. Guidelines for Synthesis and Processing of Two-Dimensional Titanium Carbide (Ti3C2Tx MXene). Chem. Mater. 2017, 29, 7633-7644. [CrossRef]

46. Li, C.; Zhang, X.; Wang, K.; Sun, X.; Ma, Y. Accordion-like titanium carbide (MXene) with high crystallinity as fast intercalative anode for high-rate lithium-ion capacitors. Chin. Chem. Lett. 2020, 31, 1009-1013. [CrossRef]

47. Maleski, K.; Ren, C.E.; Zhao, M.Q.; Anasori, B.; Gogotsi, Y. Size-Dependent Physical and Electrochemical Properties of TwoDimensional MXene Flakes. ACS Appl. Mater Interfaces 2018, 10, 24491-24498. [CrossRef]

48. Liu, C.; Wu, W.; Shi, Y.; Yang, F.; Liu, M.; Chen, Z.; Yu, B.; Feng, Y. Creating MXene/reduced graphene oxide hybrid towards highly fire safe thermoplastic polyurethane nanocomposites. Compos. Part B 2020, 203. [CrossRef]

49. Yu, B.; Tawiah, B.; Wang, L.Q.; Yin Yuen, A.C.; Zhang, Z.C.; Shen, L.L.; Lin, B.; Fei, B.; Yang, W.; Li, A.; et al. Interface decoration of exfoliated MXene ultra-thin nanosheets for fire and smoke suppressions of thermoplastic polyurethane elastomer. J. Hazard. Mater. 2019, 374, 110-119. [CrossRef]

50. Fillon, B.; Lotz, B.; Thierry, A.; Wittmann, J.C. Self-nucleation and enhanced nucleation of polymers. Definition of a convenient calorimetric "efficiency scale" and evaluation of nucleating additives in isotactic polypropylene ( $\alpha$ phase). J. Polym. Sci. Part B Polym. Phys. 1993, 31, 1395-1405. [CrossRef]

51. Varga, J. Melting memory effect of the $\beta$-modification of polypropylene. J. Therm. Anal. 1986, 31, 165-172. [CrossRef]

52. Horvath, Z.; Sajo, I.E.; Stoll, K.; Menyhard, A.; Varga, J. The effect of molecular mass on the polymorphism and crystalline structure of isotactic polypropylene. eXPRESS Polym. Lett. 2010, 4, 101-114. [CrossRef]

53. Busse, K.; Kressler, J.R.; Maier, R.D.; Scherble, J. Tailoring of the $\alpha-$, $\beta-$, and $\gamma$-Modification in Isotactic Polypropene and Propene/Ethene Random Copolymers. Macromolecules 2000, 33, 8775-8780. [CrossRef]

54. Liu, L.; Zhao, Y.; Zhang, C.; Dong, Z.; Wang, K.; Wang, D. Morphological Characteristics of $\beta$-Nucleating Agents Governing the Formation of the Crystalline Structure of Isotactic Polypropylene. Macromolecules 2021, 54, 6824-6834. [CrossRef] 